\title{
A System for Supporting the Adoption of Pedagogical Decisions based on an Assessment of Ownership of Strategies
}

\author{
Yury B. Melnikov ${ }^{2,1^{*}}$, Natalia G. Ryzhkova ${ }^{1,2}$, Elena S. Ivukina ${ }^{2}$, and Fedor A. Barkov ${ }^{2}$ \\ ${ }^{1}$ Ural Federal Unversity, 620002, Yekaterinburg, Russia \\ ${ }^{2}$ Ural State University of Economics, 620144, Yekaterinburg, Russia
}

\begin{abstract}
Large-scale changes associated with the digitalization of all industries require from the student to have both knowledge proficiency in the subject field and the formation of critical thinking, the ability to apply and update their knowledge, and the ability to apply knowledge to solve professional problems. Of particular importance in the learning process is the formation of a student's system of goals, mastery of basic activity strategies. This requires flexible control mechanisms and monitoring to obtain a large amount of information about the current level of potential development of the student. The analysis shows the relevance of developing systems for supporting the adoption of pedagogical decisions in the context of mass education, based on a multi-aspect assessment of the results. The paper describes the author's theory of adequacy based on the fact that the quality indicator of a model can be obtained by comparing the estimated model with a model accepted as a reference model. The mathematical basis is a clear definition of strategies, their analysis and improvement based on the algebraic approach, the application of which is reflected in the formation of three components: a system of basic elements; systems of standard transformations and standard combinations of elements; an approximation mechanism designed to represent the strategy as the result of applying standard transformations and typical combinations of basic elements. It is substantiated that the results for automated (automatic) decision-making can be obtained on the basis of continuous control and evaluation activities organized according to the developed methodology. The content of the decision-making system is described on the example of a mathematics course.
\end{abstract}

\section{Introduction}

Large-scale technological changes determine the need for appropriate educational transformations. Students should actively apply and update their knowledge, have critical thinking, and solve professional problems [1].

One of the topical areas of digitalization in engineering education is the development of support systems for the adoption of pedagogical decisions based on a multi-aspect

* Corresponding author: uriimelnikov58@gmail.com 
assessment of the learning process. It is proposed to use the theory of strategies and manage learning based on assessing the level of knowledge of basic strategies as the ideological basis of the system corresponding to its goals [2]. The basis for the generation of sound recommendations is the control and evaluation activity, which has the properties of continuity and consistency [3].

A university lecture and school teacher perform many functions. In recent years, the function of managing cognitive activity of students and the formation of their competencies is necessary for independent construction and implementation of activity plans. Under these conditions, basic algorithms learning is no longer enough. Learning to formulate a system of goals and mastering basic activity strategies comes to the fore. All this requires more flexible control and monitoring mechanisms to obtain a large volume of information about the current level of potential student development. An adequate student model is a condition for making the right pedagogical decisions. In the review [4], the authors identify methodological strengths and weaknesses of current predictive learning analytics applications and provide the most up-to-date recommendations on predictive model development, use and evaluation. The study described in the article [5] provides an overview of the progress made to date in learning analytics, that uses techniques, methods, and algorithms that allow the user to discover and extract patterns in stored educational data, with the purpose of improving the teaching-learning process. The article [6] shows, how by collecting longitudinal learner and learning data from a range of resources, predictive learning analytics are used to identify learners who may not complete a course, typically described as being at risk. The topic is important for the quality organization of online learning, learning analytics can be used to measure the level of student participation in online courses [7, 8]. This study [9] presents a software application that facilitates the extraction and subsequent analysis of peer assessment-related data from Moodle Workshop activities: Moodle Workshop Data Extractor. A separate area of research is the use of educational robotics tools [10].

The research papers $[11,12]$, examplify the informational and educational environment Nomotex, in terms of using a connectionist model of knowledge introduction. This model enables to construct courses and monitor in-class learning and classroom training. The term "a knowledge quantum" is used in the system realization.

\section{Formation of the strategy proficiency}

The activity management is accomplished with a help of modeling. We identify a model as a binary system, consisting of two constituents: an interfacing component for information exchange between a prototype and its image and a reference model component for the image formalization. The author's adequacy theory is based on the fact that model quality is assessed by means of the evaluated model comparison with the reference one [13]. Activity plans are viewed as the popular reference models of any activities. We proposed to consider strategies as tools for the activity plan creation.

The strategy embraces a system of typical objectives and plans for their achievements, available resources, etc. A general scheme of a planning mechanism is shown on Fig. 1. 


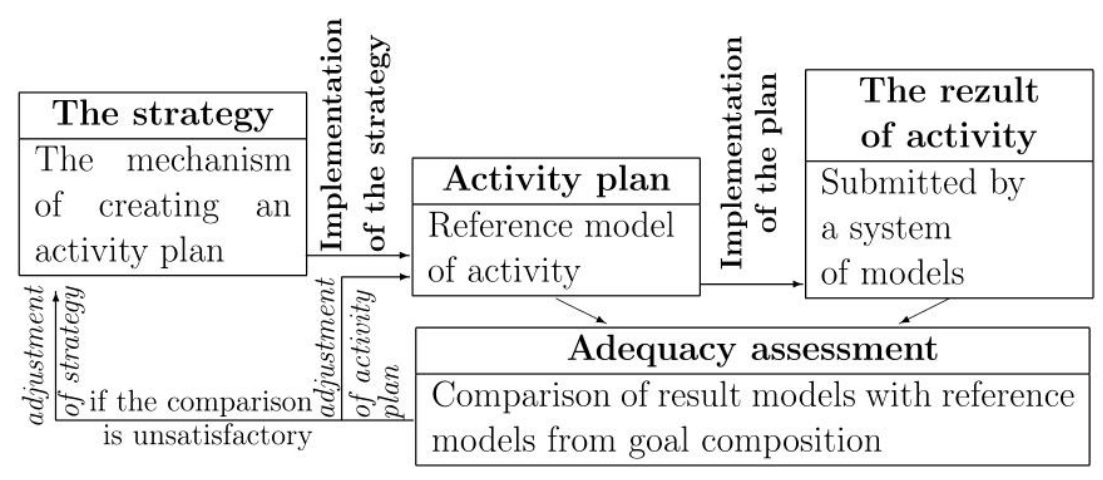

Fig. 1. Description of a planning mechanism.

Strategies and their typical plans and the precise plans of strategy implementation are defined as components of the activity management system. Definite strategy-setting, its analysis and improvement contribute to implementing an algebraic approach. In the framework of the analyzed context, the algebraic approach context is focused on forming three components: 1) the system of basic elements; 2) the system of typical conversion and typical element compositions; 3 ) the mechanism of an approximation for submission of the strategy in the form of implementation results in terms of typical conversion and typical basis element composition.

\section{Possibilities of control-assessment activity in strategy formation}

A control-assessment activity is viewed as a learning process constituent and it can be considered as a basis for realizing a pedagogic decision support system. This issue is determined by the following possibilities:

1)to actualize promptly the academic knowledge;

2)to motivate students to get knowledge for the further subject learning and the applied tasks handling skills; thus it contributes to dealing with learning material;

3) to identify the student's training level and then to divide them into focused groups; this process is very important for realizing the differentiated learning process;

4)to check the effectiveness of selected learning methods and to conduct its assessments;

5)to submit the basis for effective realization of the students' self-study.

The development and implementation of a continuous control-assessment activity in terms of above-mentioned possibilities enable:

- to measure the learning quality indicators, including the knowledge mastering completeness;

- to exert a continuous control over the student's forming of a holistic perception for providing interdisciplinary relationships among them in terms of analyzing element and structure unity as well as a part and an integrated whole;

- to track the educational achievement development of every student.

The formation and corresponding assessment of different ways of thinking are of great attention.

The method of a continuous control-assessment activity is shown on Fig. 2. 


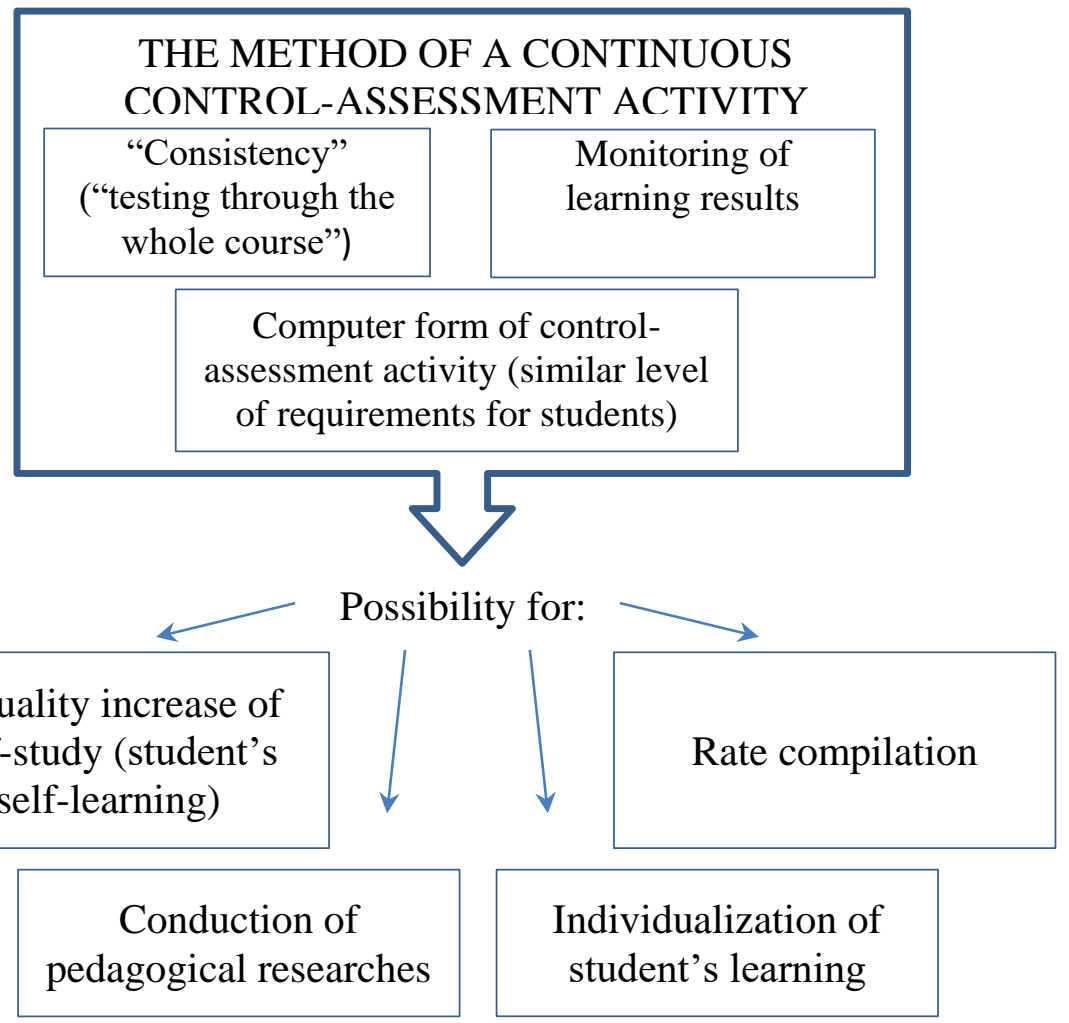

Fig. 2. The method of a continuous control-assessment activity.

To great extent, a student's self-study, its regularity and the analytical depth of studying materials, identify the learning results rating. System components enable to create a highquality foundation for students to work independently.

Rating tables are an important element of the lecturer's electronic portfolio and the necessary basis for making certain managerial decisions: correction of the proximal lecture and practical classes content, operational changes in the organization of students' independent work, taking into account their individual achievements, etc. The significance of appraisal rating for the students aims at increasing their motivation to the subject study.

The data obtained as a result of applying the system enable to conduct pedagogical research using multi-criteria assessments. The content of control and measuring materials, taking into account the different level and material development completeness, affords to implement an individual trajectory of students studying in full-time studies, viewed as an essential element of electronic educational resources, online courses.

\section{Content of the decision support system on the example of mathematics course}

Due to the spread of information and communication technologies, digitalization, science, technology, engineering and mathematics $[14,15]$ are becoming increasingly important for successful professional activities. The importance of mathematical training in engineering education and the relevance of its strengthening in some cases are shown in $[16,17,18,19$, 20]. [21] carried out a theoretical and methodological study on the critical thinking 
development through mathematical modeling in the training of engineers. In this case, mathematical modeling is considered as a didactic strategy aimed at developing not only disciplinary, but also transversal competencies.

In this regard, the system development for a mathematics course seems to be especially relevant in engineering training.

The formation of the ability to use an activity strategy and control of its proficiency begins with the formation of the goal composition. For example, the goal of "finding a function", in addition to the well-known reference models in the form of a formula, a graph, and a table of values (perhaps with an approximation mechanism for intermediate values of the argument), includes: a) parametric task of the function, including the situation when the dependence of its argument and its values from the parameter are set in table or graphs; $b$ ) implicit task definition $F(x, y)=C$ of the function, including the task of the function $\mathrm{F}$ using the table of values, level lines, etc. There are other reference models in the goal "to find the function".

With assignments focused on mastering the composition of the purpose, personalized individual homework tasks, given to students. These are tasks in a test form, individually generated for each student, focused on learning, so the text of the tasks usually contains hyperlinks to the corresponding sections of the electronic textbook. These tasks are checked with a help of Java-Script embedded in the pdf source file generated by pdflatex, and the acrotex extension package is used in the *.tex source file. Examples of task texts are shown in Fig. 3.

The algebra of vectors : test 2 (Ixov Yigreq Zetovich)

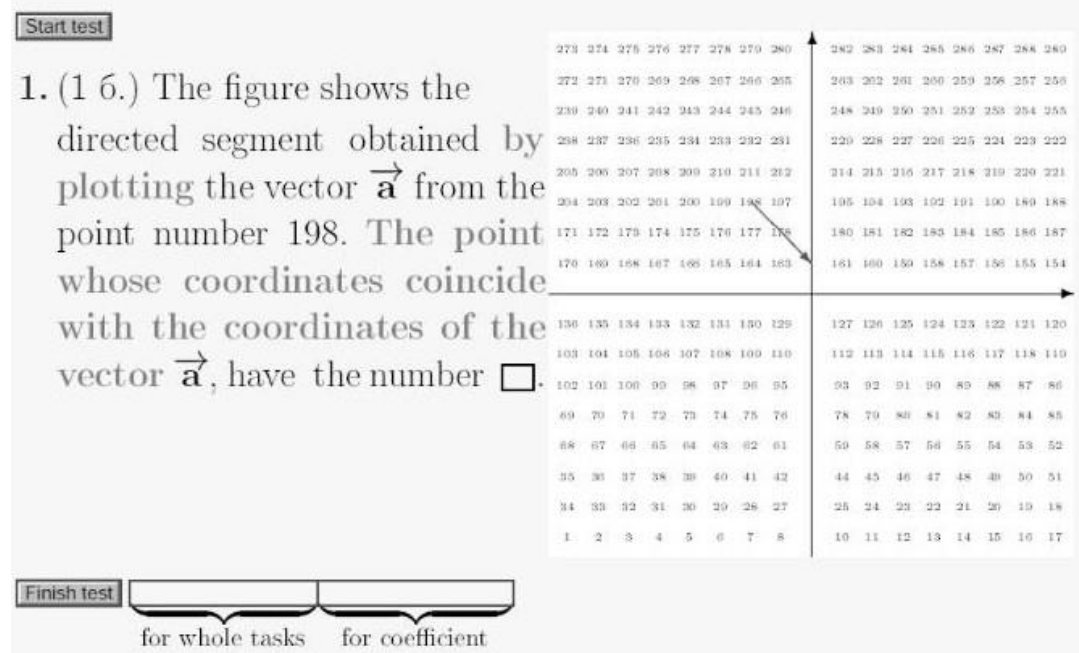

Fig. 3. Example of a task, aimed at forming a goal composition.

The task presented in fig. 3 , is based on the representation of vector algebra as a modeltriad (Fig. 4). 


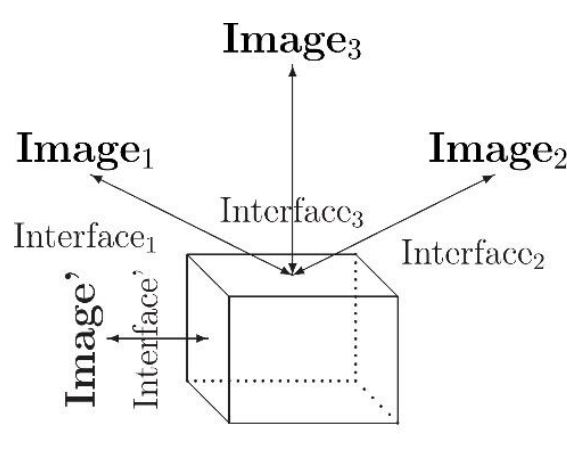

a

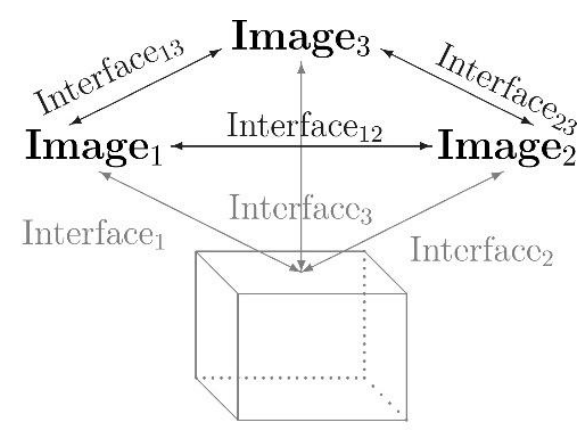

b

Fig. 4. (a, b) Illustration to the model-triad definition.

Vector algebra can be represented in the form of a model-triad, the components of which are: 1) vector-geometric model, in the framework of which we operate with directed straight line segments, considered as a result of postponing the vector from a point; 2) vector-symbolic model, the examples of the formulas of which are $(\vec{p}+2 \vec{q}) \perp(\vec{p}-\vec{q})$, $\vec{u}=3 \vec{v}-\vec{w}$ etc.; 3 ) coordinate model. Examples of tasks focused on the formation of the ability to translate information from the language of one of these models to the language of the other one are shown in Fig. 5.

\section{The algebra of vectors : test 17 (Ixov Yigreq Zetovich)}

\section{Start test}

1. (32 б.) Let $\overrightarrow{\mathbf{u}}=-9 \overrightarrow{\mathbf{i}}-3 \overrightarrow{\mathbf{j}}, \overrightarrow{\mathbf{v}}(11 ;-5)$ and $\overrightarrow{\mathbf{w}}(19 ;-37)$.

The equality $\overrightarrow{\mathbf{w}}=\tau \overrightarrow{\mathrm{u}}+\theta \overrightarrow{\mathbf{v}}$ we can present as:

$\square \overrightarrow{\mathrm{i}}+\square \overrightarrow{\mathrm{j}}=\tau(\square \overrightarrow{\mathrm{i}}+\square \overrightarrow{\mathrm{j}})+\theta(\square \overrightarrow{\mathrm{i}}+\square \overrightarrow{\mathrm{j}})$, i.e.

$\square \overrightarrow{\mathrm{i}}+\square \overrightarrow{\mathrm{j}}=\left(\square^{\prime}+\square^{\theta)} \overrightarrow{\mathrm{i}}+\left(\square \tau+\square^{\theta}\right) \overrightarrow{\mathrm{j}}\right.$

or in the coordinate form - as

$(\square ; \square)=\tau(\square ; \square)+\theta(\square ; \square)$, т.е.

$(\square ; \square)=(\square \tau+\square \theta ; \square \tau+\square \theta)$,

which is equivalent to the system of equations

$\left\{\begin{array}{l}\square=\square \tau+\square \theta, \text { for the first coordinate, } \\ \square=\square \tau+\square \theta \text { for the second coordinate. }\end{array} \quad\left\{\begin{array}{l}\tau=\square, \\ \theta=\square .\end{array}\right.\right.$

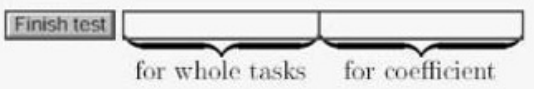

Fig. 5. An example of a task, oriented to skills forming in terms of translating from one language model to the other language model in the algebra of vectors.

In recent years, it is assumed that the purpose of training is not limited only to the formation of professional knowledge and skills, other competencies also play an important role. For example, professional activity requires the ability and experience to work with errors, which includes not only the ability to detect and correct them, but also to use them constructively. It is worth noting that some scientific methods are involved in making a mistake. For example, the method of reasoning "on the contrary" is based on the study of an erroneous statement, which can be interpreted as a deliberate mistake. When formulating a hypothesis, consideration of particular cases and the use of unsubstantiated assumptions are often used. 
It seems to us that the task of a comprehensive formalization of learning objectives remains relevant, especially in connection with the expanding practice of introducing elearning elements. The developed system of pedagogical decision support is based on the formalization of learning objectives using a design called the system of balanced strategies. The idea is to evaluate the level of, for example, mathematical training using assessments vectors of the proficiency level of important strategies in terms of mathematical activity. Examples of assessments of the proficiency strategy level are: 1) the time spent on perceiving the task; 2) the time spent on the decision; 3) the number of problems solved in a certain time, etc. In these terms, the goal of teaching mathematics can be represented as the inclusion of a vector of assessments of the possession of a strategy in the target area (the boundaries of which are set, for example, by a system of inequalities). As a result of solving a training problem using a specific strategy, the ownership of this strategy improves, see. Fig. 6.

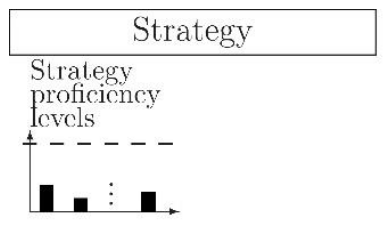

a

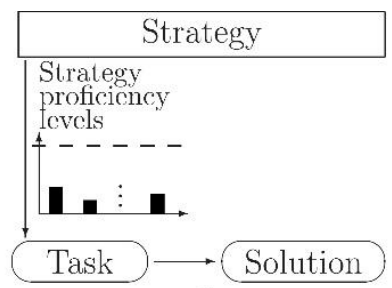

б

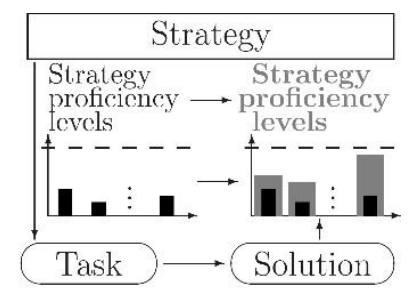

B

Fig. 6. Illustration to the management of parameters the ownership of the strategy.

\section{Conclusions}

The pedagogical decision support system is designed, firstly, to obtain relevant values of the components of the vector of assessments of the strategy's ownership by a particular student, secondly, to forecast the changes in this vector as a result of certain tasks, thirdly, to select tasks for a group of students or even a particular student, providing the movement of the vector of assessments in the target area with the least expenditure of resources (certain resources, for example, time, or a weighted estimate of the total expenditure all resources), to ensure a certain stability of the vector estimates preserve knowledge of its components after a certain period of time, and so on.

\section{References}

1. C. Pinto, S. Nicola, J. Mendonça, D. Velichová, Best teaching practices in the first year of the pilot implementation of the project DrIVE-MATH, Teaching Mathematics and its Applications: An International Journal of the IMA, 38 (3), pp. 154-166 (2019). https://doi.org/10.1093/teamat/hrz004.

2. Yu.B. Melnikov, I.B. Khripunov, B.S. Chopovda, Algebraic approach to the strategy of project activity, Bulletin of USUE, 2 (53), pp. 115 - 123 (2014).

3. N.G. Ryzhkova, Professional training quality improvement on the basis of continuous testing system, LAP LAMBERT Academic Publishing, p. 333, ISBN: 978-3-65930682-2 (2013).

4. Y. Cui, F. Chen, A. Shiri, Y. Fan, Predictive analytic models of student success in higher education: A review of methodology, Information and Learning Science, 120 (34), pp. 208-227 (2019). DOI: 10.1108/ILS-10-2018-0104. 
5. D. Buenaño-Fernandez, W. Villegas-CH, S. Luján-Mora, The use of tools of data mining to decision making in engineering education - A systematic mapping study, Computer Applications in Engineering Education, 27(3), pp. 744-758 (2019). https://doi.org/10.1002/cae.22100.

6. C. Herodotou, B. Rienties, A. Boroowa, Z. Zdrahal, M. Hlosta, A large-scale implementation of predictive learning analytics in higher education: the teachers' role and perspective, Educational Technology Research and Development, 67 (5), pp. 1273-1306 (2019). https://doi.org/10.1007/s11423-019-09685-0.

7. S.S. Adji, S. Hamda, Utilization of learning analytic on measuring student participation in online learning, Journal of Physics: Conference Series 1280(3), 032014 (2019), 6th International Seminar on Mathematics, Science, and Computer Science Education, MSCEIS 2018, 155271 (2019). DOI: 10.1088/17426596/1280/3/032014.

8. B.S. Horvitz, L.R. Garcia, R.G. Mitchell, Ch.D. Calhoun, An examination of instructional approaches in online technical education in community colleges, ONLINE LEARNING, 23(4), pp. 237-252 (2019).

9. E. Acquila-Natale, S. Iglesias-Pradas, A. Hernández-García, J. Chaparro-Peláez, I. Rodríguez-Ruiz, MWDEX: A moodle workshop data Extractor, ACM International Conference Proceeding Series, 16 October 2019, pp. 297-303, 7th International Conference on Technological Ecosystems for Enhancing Multiculturality, TEEM 2019; Leon; Spain, 2019, 154355 (2019).

10. C. Giang, A. Piatti, F. Mondada, Heuristics for the development and evaluation of educational robotics systems, IEEE Transactions on Education 62(4), pp. 278-287, 8703426 (2019). DOI: 10.1109/TE.2019.2912351.

11. Yu.I. Dimitrienko, E.A. Gubareva, Hierarchical neural network model for mathematical knowledge and software NOMOTEX for mathematical training of engineers, IOP Journal of Physics: Conference Series, 1141 (1), 012010 (2018). DOI: 10.1088/1742-6596/1141/1/012010.

12. Yu.I. Dimitrienko, E.A. Gubareva, A new technology of mathematical training of engineering personnel, based on a neural network model of knowledge, Educational innovation, 11, pp. 129 - 140 (2017).

13. Yu.B. Melnikov, M.D. Boyarskiy, M.D. Lokshin, The prospective economists and engineers forming skills for diversified activity assessment in the mathematics learning process, Contemporary education 4, pp. 74-90 (2018). DOI: 10.25136/24098736.2018.4.27930. - URL:http://nbpublish.com/library_read_article.php?id=27930

14. N.J. van der Wal, A. Bakker, P. Drijvers, Teaching strategies to foster technomathematical literacies in an innovative mathematics course for future engineers, ZDM Mathematics Education 51, pp. 885-897 (2019). https://doi.org/10.1007/s11858019-01095-Z.

15. S.A. Helmi, Mohd-Yusof Khairiyah and Hisjam Muhammad, Enhancing the implementation of science, technology, engineering and mathematics (STEM) education in the 21st century: A simple and systematic guide, AIP Conference Proceedings 2097, 020001 (2019). https://doi.org/10.1063/1.5098172.

16. S. Nieto-Isidro, H. Ramos, General versus specific recipients for online training courses: Evaluating an experience on basic mathematics for engineers, ACM International Conference Proceeding Series16 October 2019, pp. 756-762, 7th International Conference on Technological Ecosystems for Enhancing Multiculturality, TEEM 2019, 154355 (2019). https://doi.org/10.1145/3362789.3362892. 
17. A. Vintere, B. Briede, Methodical background of competence-based mathematics education for students of information technologies specialties, Engineering for Rural Development 18, pp. 1947-1953 (2019). DOI: 10.22616/ERDev2019.18.N4.

18. P. Yakimov, Towards attractive STEM education by using open source hardware and software, IEEE 27th International Scientific Conference Electronics, ET 2018 Proceedings 8549579 (2018).

19. S. Pohjolainen, T. Myllykoski, C. Mercat, S. Sosnovsky, Modern mathematics education for engineering curricula in europe: A Comparative Analysis of EU, Russia, Georgia and Armenia, pp. 1-196 (2018). https://doi.org/10.1007/978-3-319-71416-5.

20. C. Andersson, D. Logofatu, Using cultural heterogeneity to improve soft skills in engineering and computer science education, IEEE Global Engineering Education Conference, EDUCON 2018-April, pp. 191-195 (2018).

21. J. Acebo, R. Rodríguez, Theoretical and methodological proposal on the development of critical thinking through mathematical modeling in the training of engineers, Proceedings of the Seventh International Conference on Technological Ecosystems for Enhancing Multiculturality (TEEM 2019) (León, Spain, October 16-18, 2019), ACM, New York, NY, USA, pp. 941-948 (2019). https://doi.org/10.1145/3362789.3362828. 